\title{
Additional concerns for the scavenging of anesthetic agents used for ICU sedation
}

\author{
Hilary P. Grocott ${ }^{1}$
}

Received: 24 July 2018 / Accepted: 30 July 2018 / Published online: 1 August 2018

(c) Springer Nature B.V. 2018

\section{To the Editor:}

The recent review article by Herzog-Niescery et al. outlines the increasing use of inhaled anesthetic agents for sedation in the intensive care unit (ICU) [1]. In addition to discussing the potential concerns regarding trace gas exposure, the article also addresses the solutions to this, including the use of several anesthetic gas scavenging systems. However, absent from their discussion was that the systems that have thus far been used, including the Deltasorb® (Blue Zone; Concord, ON, Canada) [2], rely on conventional hospital vacuum systems to function. It has been previously pointed out [3] that these systems may not necessarily meet the ISO (Organization for International Standardization) standards [4] for the use of anesthetic gas scavenging disposal systems, and thus, may represent a potential safety hazard. Though this has been argued to be less of a significant issue than once thought [5], most ICUs have not been designed a priori for the use of anesthetic agents and accordingly, all of the necessary safety considerations need to be fully taken into account.

Author contributions Dr. Grocott contributed to the concept and the writing of this letter.

\section{Compliance with ethical standards}

Conflict of interest The authors declare that they have no conflict of interest.

\section{References}

1. Herzog-Niescery J, Seipp HM, Weber TP, Bellgardt M. Inhaled anesthetic agent sedation in the ICU and trace gas concentrations: a review. J Clin Monit Comput. 2018;32(4):667-75. https://doi. org/10.1007/s10877-017-0055-6.

2. Wong K, Wasowicz M, Grewal D, Fowler T, Ng M, Ferguson ND, Steel A, Jerath A. Efficacy of a simple scavenging system for longterm critical care sedation using volatile agent-based anesthesia. Can J Anaesth. 2016;63(5):630-2. https://doi.org/10.1007/s1263 0-015-0562-1.

3. Dain SL. Anesthesia scavenging in critical care areas: beware of possible hazards and questionable efficacy. Can J Anaesth. 2017;64(1):96-7. https://doi.org/10.1007/s12630-016-0744-5.

4. International Organization for Standardization ISO 7396-2 Medical gas pipeline systems - part 2: anaesthetic gas scavenging disposal systems. (2007). http://www.iso.org/standard/41945.html. Accessed July 2018.

5. Jerath A, Wasowicz M. In reply: anesthesia scavenging in critical care areas: beware of possible hazards and questionable efficacy. Can J Anaesth. 2017;64(1):98-9. https://doi.org/10.1007/s1263 0-016-0745-4.
Hilary P. Grocott

hgrocott@sbgh.mb.ca

1 Department of Anesthesiology, Perioperative \& Pain Medicine, University of Manitoba, CR3008 - 369 Tache Avenue, Winnipeg, MB R2H 2A6, Canada 